\title{
Application Research on Two Types of 8QAM-OFDM Optical Access Signals
}

\author{
Yufeng Shao, Junyi Zhou, Zhifeng Wang, Yiying Hu, Yue Zhou, Changxiang Li, Wengzhe Ma \\ Faculty of Engineering, Shanghai Polytechnic University, Shanghai, China \\ Email: syufeng@163.com
}

Received 1 July 2016; accepted 18 August 2016; published 25 August 2016

\begin{abstract}
In this paper, the downstream transmission performance of two types of 8QAM-OFDM optical signals in broadband optical access system has been analyzed. After modulation and coding, two types of $10 \mathrm{Gbit} / \mathrm{s}$ 8QAM-OFDM optical access signals are downstream transmitted over $1 \mathrm{~km}, 10$ $\mathrm{km}, 20 \mathrm{~km}$ and $40 \mathrm{~km}$ single mode fibers (SMFs) and received successfully. Different transmission distances impact on the bit error rate (BER) of the received signal is analyzed by simulation, while the signal to noise ratio (SNR) is $20 \mathrm{~dB}$. The results show that, while the transmission distance is shorter than $10 \mathrm{~km}$, the BER values of two types of 8QAM-OFDM optical signals are smaller than $1^{-10}$. As the above optical access signals are transmitted over $40 \mathrm{~km}$ SMF, the BER value of the first type of 8QAM-OFDM signals is bigger than $10^{-6}$, and the BER of the other type of 8QAM-OFDM signals is smaller than $10^{-6}$.
\end{abstract}

\section{Keywords}

Optical Access System, OFDM, QAM, SNR, BER

\section{Introduction}

At present, with the rapid increase of the types and number of broadband communication access services, the development trend of optical access system is mainly focused on high frequency band utilization and user bandwidth [1]-[4]. Orthogonal frequency division multiplexing (OFDM) optical access technology as a multi-carrier modulation technology has received more and more researcher's attention [5] [6]. The reason is that it has a good ability to resist chromatic dispersion (CD) and polarization mode dispersion (PMD), and the spectrum utilization rate is high and the flexible multi-service bandwidth allocation can be realized by using a large number of sub carriers [7] [8]. In this paper, the downstream transmission of two types of 8QAM-OFDM optical signals in broadband optical access system has been compared and analyzed. After modulation and coding in this scheme, the two types of 8QAM-OFDM optical access signals are downlink transmitted successfully over single mode fiber (SMF) with $1 \mathrm{~km}, 10 \mathrm{~km}, 20 \mathrm{~km}$ and $40 \mathrm{~km}$ distance at $10 \mathrm{Gbit} / \mathrm{s}$. Different transmission distances impact on the bit error rate (BER) of the received signal is analyzed by simulation, while the signal to noise ratio (SNR) is $20 \mathrm{~dB}$. 


\section{System Analysis}

We propose and simulate the 8QAM-OFDM optical access system structure diagram as shown in Figure 1. At the transmitter side of the downlink, the $10 \mathrm{Gbit} / \mathrm{s}$ input data is modulated by 8QAM, and then 8QAM electric signals are S/P conversed, IFFT processed, P/S conversed and added cyclic prefix (CP) operation. And then, 10 Gbit/s 8QAM-OFDM electrical signals are generated. Through one cavity laser External (ECL), one continuous optical carrier is generated which line width is $100 \mathrm{kHz}$ and the working wavelength is $1550 \mathrm{~nm}$. The generated optical carrier is input to one Mach-Zehnder modulator (MZM). Simultaneously, 10 Gbit/s 8QAM-OFDM electric signals are input to the MZM for generating 8QAM-OFDM optical signals.

When 8QAM-OFDM optical signals are passed through the single mode fiber (SMF), it is amplified by one tunable erbium doped fiber amplifier (EDFA) to compensate attenuation in the optical fiber link. At the receiver, a high sensitivity photo-diode (PIN) is used to detect the $10 \mathrm{Gbit} / \mathrm{s} 8 \mathrm{QAM}-\mathrm{OFDM}$ optical access signal and complete the photoelectric conversion, and the generated 8QAM-OFDM electrical signal is connected to an electric amplifier (EA). The amplified electrical signal is divided into two ways. After the implementation of phase adjustment by one adjustable phase shifter, one is input to the electric mixer for direct mixing with another signal to complete the coherent detection process. A low pass filter (LPF) with the bandwidth of $7.5 \mathrm{GHz}$ is used, and thus $10 \mathrm{Gbit} / \mathrm{s}$ 8QAM-OFDM electrical signals are restored. The detected signal is implemented S/P conversed, removed CP, FFT processed, P/S conversed and 8QAM demodulated. At last, $10 \mathrm{Gbit} / \mathrm{s}$ data are restored. It is worth noting that, in the 8QAM modulation, two constellation diagrams are generated respectively for mapping two types of 8QAM-OFDM electrical signals. The external shapes of the related constellation diagrams are diamond and rectangular, respectively. The constellation diagrams are shown in Figure 1(i) and Figure 1(ii). Considering the phase sensitivity, the phase matching process must be realized by adjusting the tunable phase shifter, whose dynamic adjustment range is from 0 to 360 degree. By using an optical spectrum analyzer (OSA) in which the $3 \mathrm{~dB}$ resolution bandwidth is $0.02 \mathrm{~nm}$, the optical spectral diagrams of the first type of 8QAMOFDM optical signals before and after transmission over $1 \mathrm{~km}, 10 \mathrm{~km}, 20 \mathrm{~km}, 30 \mathrm{~km}, 40 \mathrm{~km}$ SMF are shown in Figure 2 and Figure 3. The similar optical spectral diagrams are shown in Figure 4 and Figure 5, when the second type of 8QAM-OFDM optical signals is transmitted.
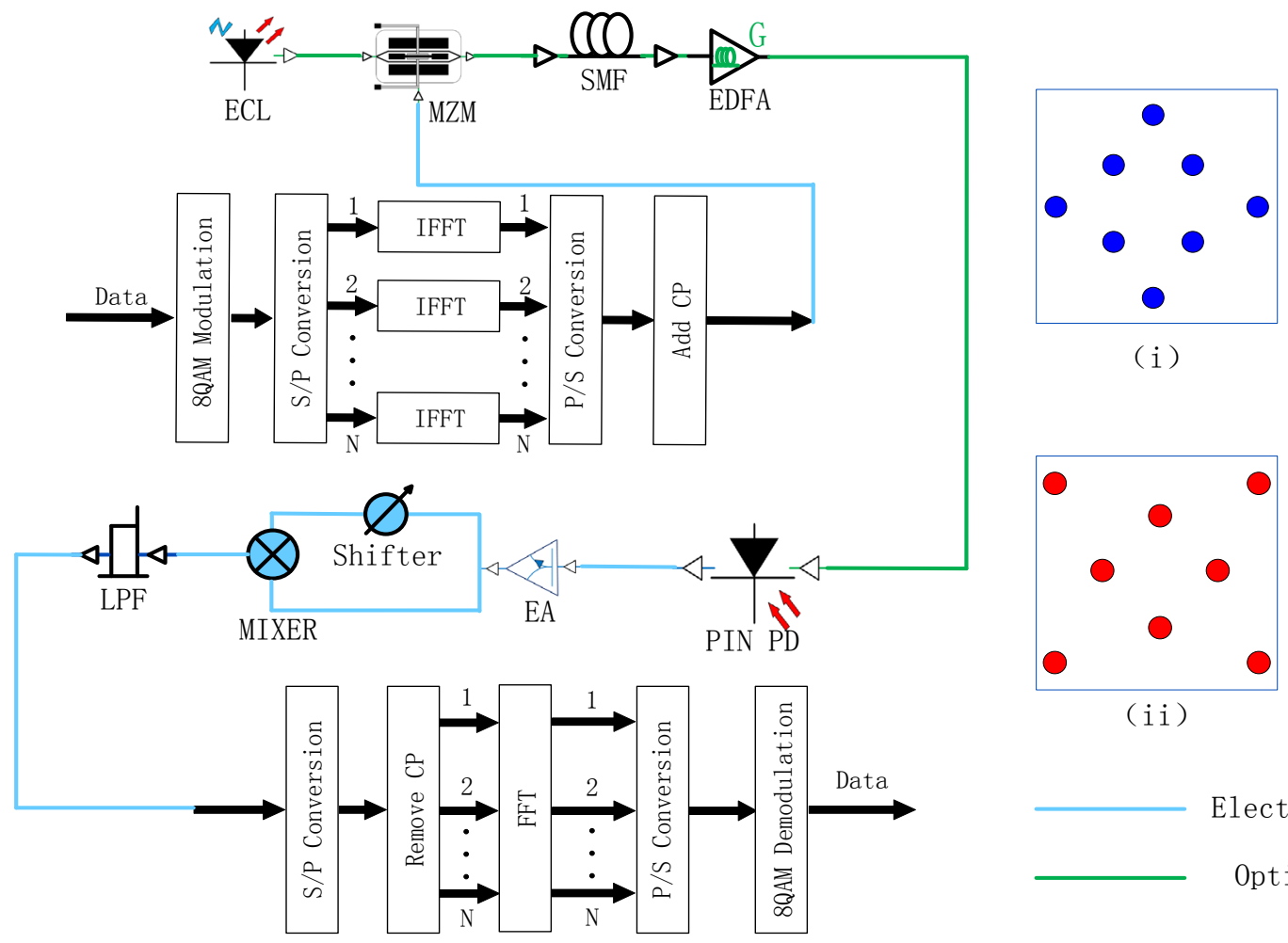

(i)

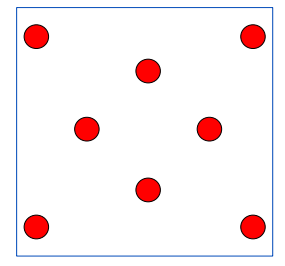

(ii)

Figure 1. Schematic diagram of 8QAM-OFDM optical access system. 

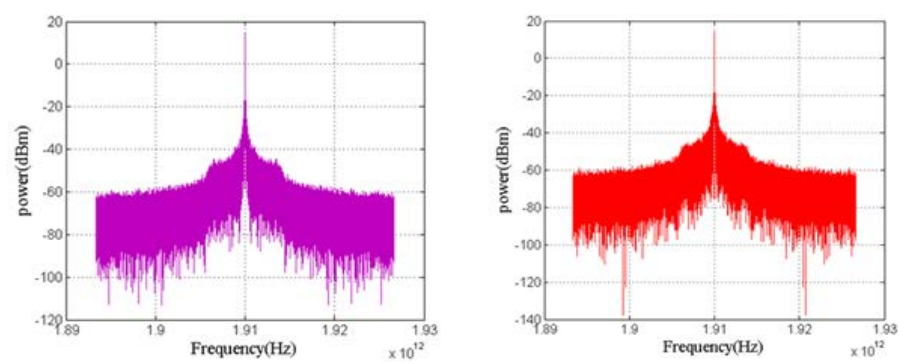

Before $1 \mathrm{~km}$

Before $10 \mathrm{~km}$

Before 20km

Before $30 \mathrm{~km}$

Before $40 \mathrm{~km}$
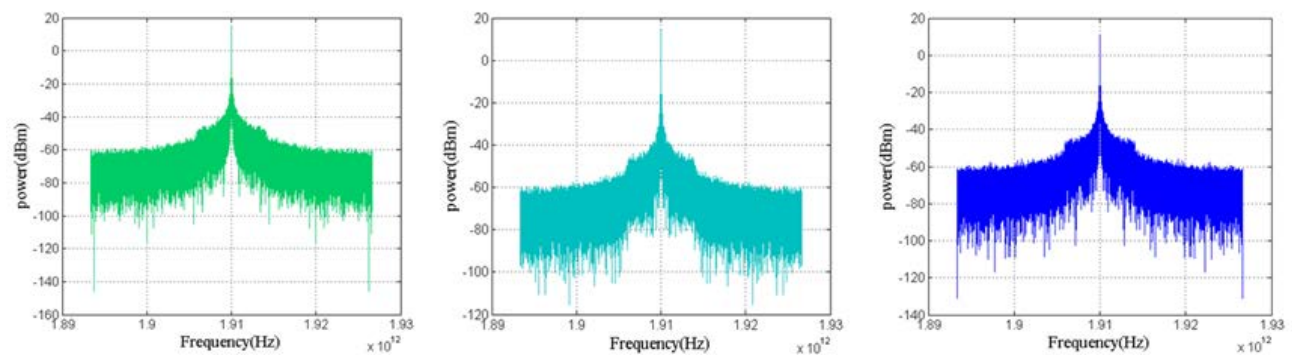

Figure 2. Optical spectral diagrams of the first type of 8QAM-OFDM optical access signals before transmission over different length SMFs.
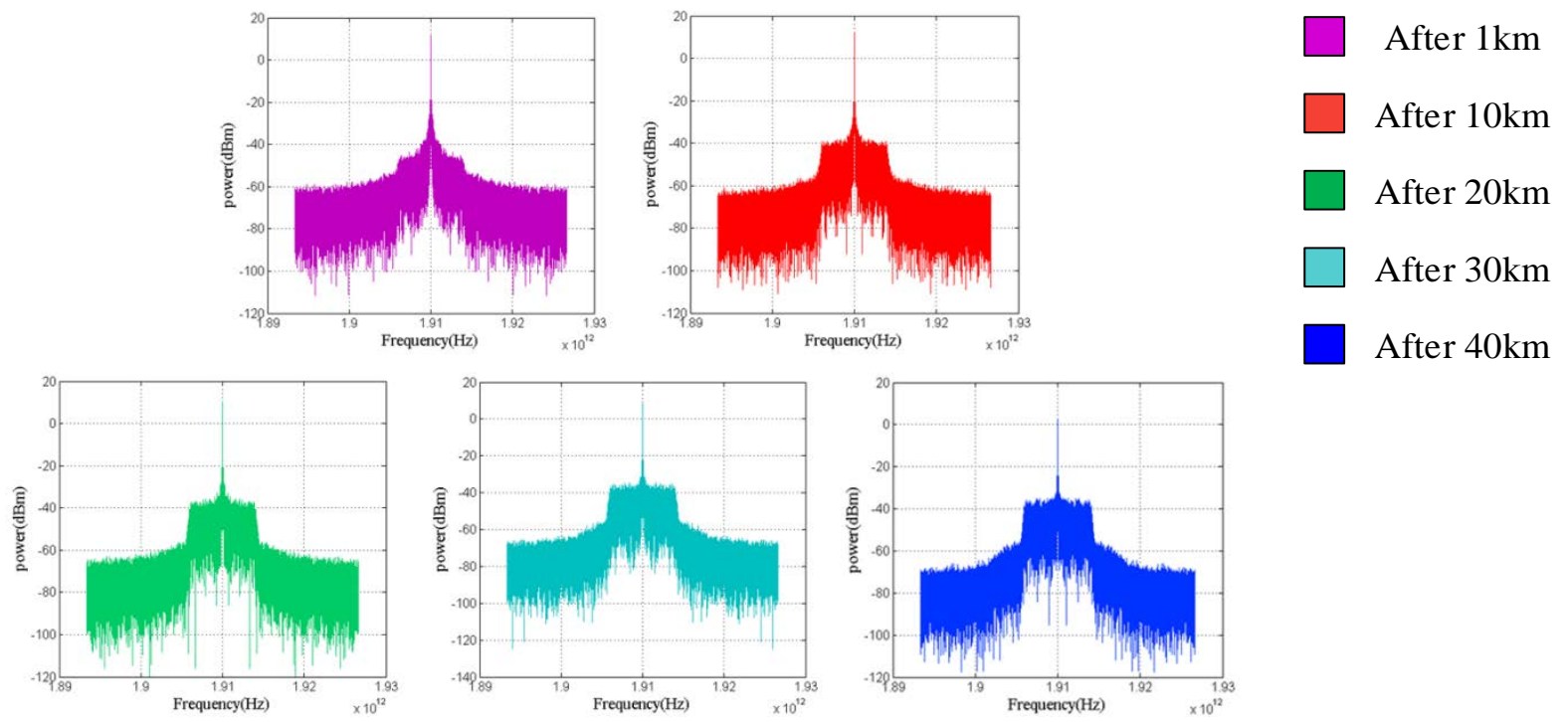

Figure 3. Optical spectral diagrams of the second type of 8QAM-OFDM optical access signals after transmission over different length SMFs.

After transmission, as the received signal to noise ratio (SNR) of the $10 \mathrm{Gbit} / \mathrm{s}$ 8QAM-OFDM signals is 20 $\mathrm{dB}$, the relationship between the bit error rate (BER) and different optical links leng this shown in Figure 6. It is clear to see, if the transmission distance is longer, the values of the BER of the two 8QAM-OFDM optical access signals will increase. As the transmission distance is less than $10 \mathrm{~km}$, the BER values of two types of 8QAM-OFDM optical access signals are lower than $10^{-10}$. While the transmission distance is $40 \mathrm{~km}$, the BER value of the first type of 8QAM-OFDM optical access signals is bigger than $10^{-6}$, and the BER value of the second one is less than $10^{-6}$. If the downlink length is longer, the receiver sensitivity is higher for the second type of 8QAM-OFDM optical signals access application.

\section{Conclusion}

In reality, comparing with 4QAM-OFDM optical access signals, 8QAM-OFDM optical access signals have a 

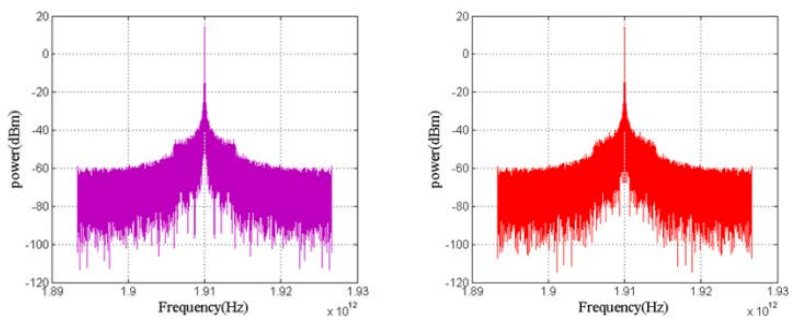

Before $1 \mathrm{~km}$

Before $10 \mathrm{~km}$

Before 20km

Before $30 \mathrm{~km}$

Before $40 \mathrm{~km}$
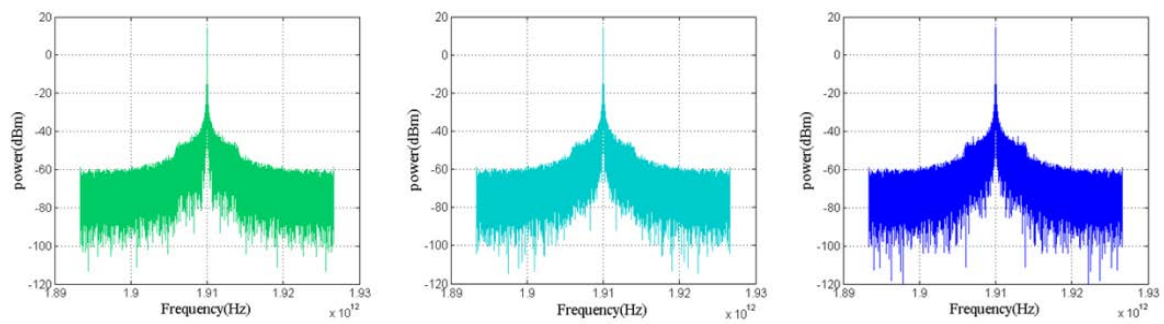

Figure 4. Optical spectral diagrams of the first type of 8QAM-OFDM optical access signals before transmission over different length SMFs.
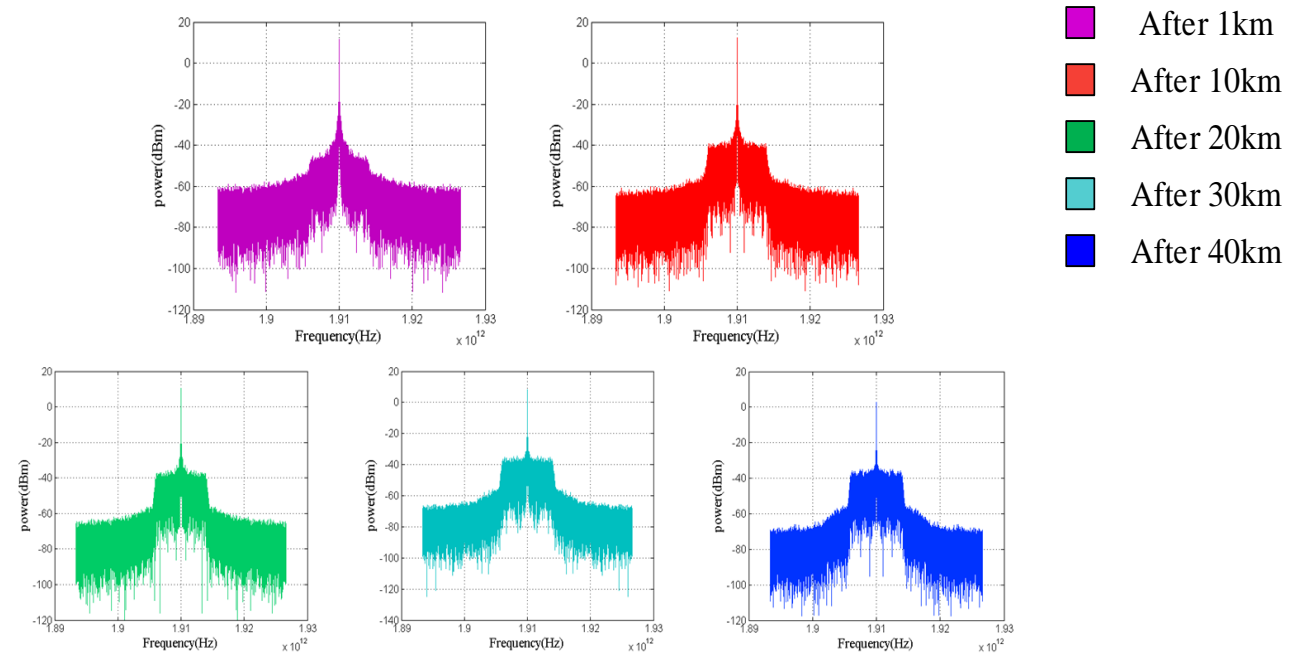

Figure 5. Optical spectral diagrams of the second type of 8QAM-OFDM optical access signals after transmission over different length SMF.
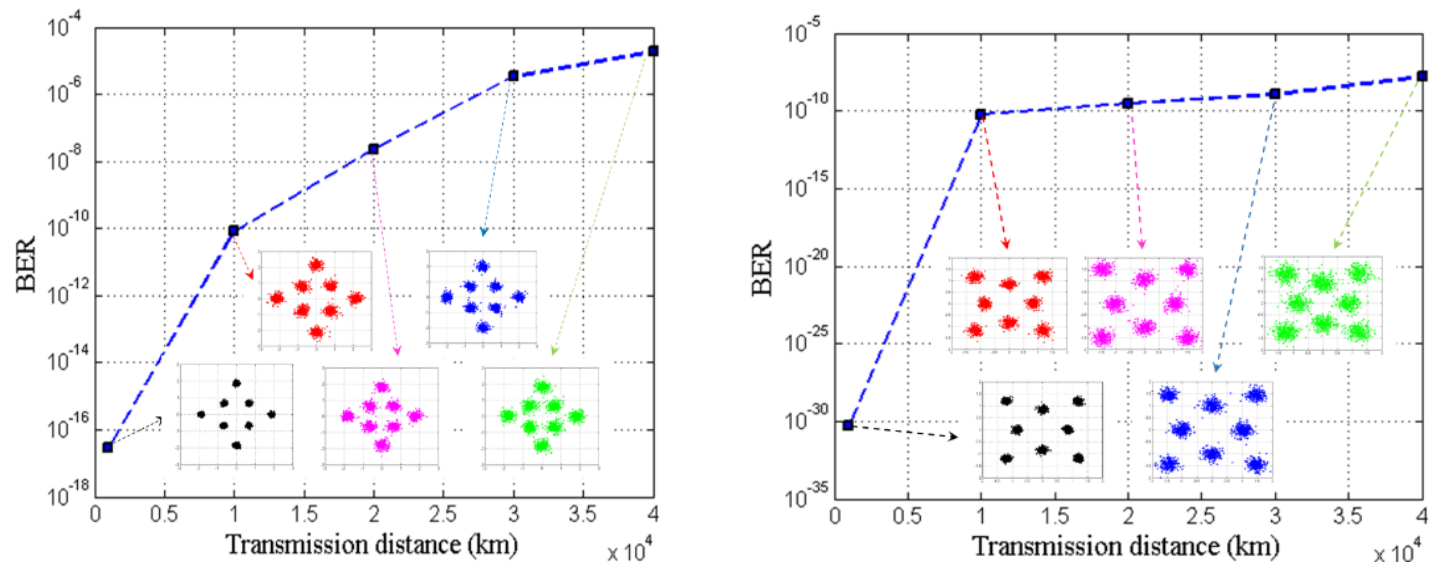

Figure 6. The BER of two types of 8QAM-OFDM optical access signals at SNR $=20 \mathrm{~dB}$. 
higher frequency band utilization rate, and with respect to the 16QAM-OFDM optical signals, the digital signal processing (DSP) process of 8QAM-OFDMis simpler. But, in broadband optical access system, the transceiver performance of 8QAM-OFDM optical access signals with different constellation mapping. The results show that, when the transmission distance is shorter than $10 \mathrm{~km}$, the BER values of two types of 8QAM-OFDM optical signals are smaller than $10^{-10}$. As the above optical access signals are transmitted over $40 \mathrm{~km} \mathrm{SMF}$, the BER value of the first type of 8QAM-OFDM signals is bigger than $10^{-6}$, and the BER of the other type is otherwise. Therefore, as the downlink is shorter than $10 \mathrm{~km}$, two types of 8QAM-OFDM optical signals with different constellation mapping can adopted. While the downlink distance is $40 \mathrm{~km}$ or longer, the second type of 8QAMOFDM optical access signals is the optimal for achieving high receiver sensitivity.

\section{Acknowledgements}

This work is partially supported by the National Natural Science Foundation of China (No. 61107064), Innovation Program of Shanghai Municipal Education Commission (No. 15ZZ101), Leading Academic Discipline Project of Information and Communication Engineering (No. XXKZD1605), School Foundation (No. EGD14XQD01) of Shanghai Second Polytechnic University, College Students' Science and Technology Innovation Project of Shanghai Second Polytechnic University (No. 2016-xjkj-063), and College Student Innovation Activity Plan in Shanghai (No. 2013-sj-cxjh-028).

\section{References}

[1] Shao, Y.F., Wang, Y.J. and Chi, N. (2013) 60-GHz RoF System with Low PAPR 16QAM-OFDM Downlink Using PTS Segmentation. IEEE Photonics Technology Letters, 25, 855-858. http://dx.doi.org/10.1109/LPT.2013.2252425

[2] Shao, Y.F., Chi, N., Fan, J.Y. and Fang, W.L. (2012) Generation of 16-QAM-OFDM Signals Using Selected Mapping Method and Its Application in Optical Millimeter-Wave Access System. IEEE Photonics Technology Letters, 24, 13011303. http://dx.doi.org/10.1109/LPT.2012.2202387

[3] Shao, Y.F., Zhang, J.W., Fang, W.L., Huang, B., Zhang, Z.R. and Tao, L. (2010) DRZ, DQPSK, and PoISK Orthogonal Modulations for 100Gbit/s Transmission System Applications. Asia Communications and Photonics Conference and Exhibition, 142-143. http://dx.doi.org/10.1109/ACP.2010.5682795

[4] Shao, Y.F., Wang, J.J., Wang, L.D., et al. (2014) Adopting Adaptive Nyquist Filtering Technique in 100 Gb/s Coherent Dual Polarization Optical OFDM Systems. Asia Communications and Photonics Conference, ACP, Shanghai.

[5] Shao, Y.F. (2016) PAPR Reduction and Receiver Sensitivity Improvement in 16QAM-OFDM RoF System Using DMT Modulation and BTN-PS Technique. Optical and Laser Technology, 77, 59-63. http://dx.doi.org/10.1016/j.optlastec.2015.08.013

[6] Ali, M., Dai, B. and Wang, X. (2014) Performance Evaluation of Super Channels Using All-Optical M-QAM OFDM and Coherent Receiver in the Presence of Time and Frequency Offsets. 2014 9th International Conference on Communications and Networking in China (CHINACOM), 293-297. http://dx.doi.org/10.1109/CHINACOM.2014.7054304

[7] Li, P., Zhu, Y., Wang, Z.X. and Wang, N.B. (2010) Peak-to-Average Power Ratio of SC-FDMA Systems with Localized Subcarrier Mapping. Mobile, 1-6. http://dx.doi.org/10.1109/gmc.2010.5634563

[8] Shao, Y.F. and Chi, N. (2012) A Novel Scheme for Seamless Integration of RZ-DPSK-DWDM Optical Links with MIMO-OFDM System. Microwave and Optical Technology Letters, 54, 1676-1679. http://dx.doi.org/10.1002/mop.26891 


\section{Submit or recommend next manuscript to SCIRP and we will provide best service for you:}

Accepting pre-submission inquiries through Email, Facebook, LinkedIn, Twitter, etc.

A wide selection of journals (inclusive of 9 subjects, more than 200 journals)

Providing 24-hour high-quality service

User-friendly online submission system

Fair and swift peer-review system

Efficient typesetting and proofreading procedure

Display of the result of downloads and visits, as well as the number of cited articles

Maximum dissemination of your research work

Submit your manuscript at: http://papersubmission.scirp.org/ 